Marquette University

e-Publications@Marquette

$12-1-1979$

\title{
The Role of The Father in Child Development: A Review Of The Literature
}

\author{
J. Frank Popplewell
}

Anees A. Sheikh

Follow this and additional works at: https://epublications.marquette.edu/psych_fac

Part of the Psychology Commons 


\title{
Marquette University
}

\section{e-Publications@Marquette}

\section{Psychology Faculty Research and Publications/College of Arts and Sciences}

\author{
This paper is NOT THE PUBLISHED VERSION; but the author's final, peer-reviewed \\ manuscript. The published version may be accessed by following the link in the citation below.
}

International Journal of Social Psychiatry, Vol. 25, No. 4 (December 1, 1979): 267-284. DOI. This article is (C) Sage Publications and permission has been granted for this version to appear in ePublications@Marquette. Sage Publications does not grant permission for this article to be further copied/distributed or hosted elsewhere without the express permission from Sage Publications.

\section{The Role of The Father in Child Development: A Review Of The Literature}

\author{
J. Frank Popplewell and Anees A. Sheikh \\ Marquette University
}

Traditionally, the role of the father in the psychological development of children has received relatively little attention. Recently, however, an increasing number of researchers have evinced considerable interest in this area. 'Much of the current interest...seems to have been intensified by the growing awareness of the prevalence of fatherless families and the social, economic, and psychological problems that such families encounter' (Biller, 1971, p. l). the present review brings together most of the available research in this field. The first and most substantial aspect to be discussed involves the role of the father in the sex-role development of children. Although there are a few studies that have dealt with the development of femininity in girls and its relationship to various paternal factors, the emphasis in the literature has been primarily on the sex-role development of boys. The second segment of this paper will discuss the role of the father in the general personality functioning of children. This area consists almost entirely of retrospective studies, with an emphasis on factors relating to abnormality. The third category is composed of information on the father's role in the child's cognitive development. The fourth section will contain information not 
directly related to any of the first three points. The last portion of this article will present some concluding remarks and a few suggestions for future investigations.

\section{Sex-Role Development in Children}

To the Freudians, the role of the father in the development of the male child's sex-role can largely be reduced to the role the father plays in the resolution of the Oedipal complex. Anderson (1968) describes the theoretical framework by which boys come to identify with their fathers: this identification takes place in the boy as he ' ... gradually relinquishes his sense of narcissistic omnipotence and his ambition to be the sole possessor of his mother' (p. 648). As these are reduced, his aggressive rivalry with his father is neutralized through the process of identification; this is the onset of is masculine sex-role development. In psychoanalytic theory, the role of the father in the girls' sex-role development is primarily as the erotic object of the Electra complex; when she breaks free of this and identifies with the mother, his role in her development is diminished.

In a learning theory framework, the role of the father can be seen in both male and female development. To the male child he is a model: a warm, affectionate relationship and prolonged association serves as reinforcement and is conducive to identification. His importance in the developing female's life is as 'a rewarder of her sex-appropriate responses, conducive to her identification with her mother.

Several other writers, not primarily associated with either the psychoanalytic school or the learning theory, have theorized about the father's role in the development of sex-typed behaviour in children (Ahnsen, 1970; Johnson, 1963; Meerloo, 1968). For example, Johnson (1963) takes the position that it is the father who is crucial for producing appropriate sex-role orientations in both male and female children. She hypothesises that both males and females identify initially with the mother, but that this is not a sex-type identification. She further states that, although the mother shares common cultural values with the father about what is appropriate masculine and feminine behavior ' ... there is considerable evidence that she does not make a basic differentiation in her attitude toward male and female children' (p.320)

To understand Johnson's (1963) view of how the father's behavior is responsible for differentially producing sex-typed behavior in both boys and girls, it is first necessary to understand her conceptualization of masculinity and feminity which is presented in terms of an 'instrumental-expressive' dimension. 'An expressive role player is oriented toward the relationship among the actions within a system and is primarily concerned with the effective attitudes of the actors toward each other. An instrumental role player is oriented toward securing a favorable position between the system and its environment' (p. 320) She goes on to describe the family as the relevant system where ' ... the mother is the expressive leader, responsible for the care of the individual family members; the father is the instrumental leader, primarily responsible for providing for the family as a unit in the environment' (p. 320). Johnson proposes that the father, as the instrumental leader of the family, represents the outside world to his children. Thus, she reasons he is the 'stepping-stone' by way of which the children of both sexes become emancipated from their infantile love-dependency relationship with the mother. This idea receives strong support from Ahnsen's (1970, 1972) and Meerloo's (1968) theoretical and clinical work.

Carrying her argument one step further, Johnson states that '... the parent representing independence is the parent responsible for sex-role learning, because it seems clear that sex-role 
internalization should take place in a context of at least relative emancipation from infantile dependency' (p. 323). According to her, the father further differentiates the sexes by playing husband to the girl and mentor to the boy. It is quite clear that Johnson makes a leap from the 'father initiating sex-role development' (which he may or may not do) to the 'father being responsible for sex-role learning'. The latter position seems to imply that the mother plays a negligible role in sex-typing, but this is not indicated by the data available at the time she wrote the article. Looking past her theoretical foundations, however, it will be seen that certain aspects of her conclusions are justified by later studies. The remainder of this section will concentrate on the research findings in this area.

Mussen and Rutherford (1963) found that the perceived nurturance of both parents was important to the developing sex roles of boys and girls. The most crucial determinant of the development of masculinity was the nature of the father-son relationship. Appropriate sex-role preference in males was found to be directly related to nurturant, affectionate relationships with the father. They also found a tendency for high masculine boys to perceive their fathers as punitive and threatening, which they viewed as being consonant with the idea of identification with the aggressor. Significantly, they also found that 'there was no evidence in their data that high masculinity of fathers, femininity of mothers, parental self-acceptance, or parental encouragement of sons success in masculine activities had any effect on boys' masculinization' (p. 606). From their results, they concluded in part that '... the boy's perception of his father as a nurturant and powerful individual is important, but the parents' personality structures and their pressures toward sex-typing their son are not influential' (p.606).

With respect to feminization of girls. Mussen and Rutherford found that while it is important that there exist a warm mother-daughter relationship it is also facilitative for her to have a masculine father who rewards her for participation in appropriate sex-typed activities, fostering her development of femine role preference. These findings seem to cast some doubt on Johnson's (1963) belief that the father is the role differentiator; according to these findings the mother plays the major role in feminization of her daughter.

Hetherington and Frankie (1967) investigated the relation between projective measures of 160 male and female kindergartners' sex-role preference and ratings of dominance, warmth, and restrictiveness of their parents, as assessed by a structured Family Interaction Task. They found that paternal warmth and power is important to girls' sex role development; that paternal dominance is important in male development; and that identification with the aggressor is seen in restricted conditions involving high stress and low warmth in both parents. They conclude that, if the father is dominant and both parents are nurturant, then normal sex-typing will occur; if both parents are lownurturant, however, there is a tendency for children to identify with the stronger of the two.

Greenstein (1969) presents some interesting commentary on the unqualified acceptance of 'nurturance' as an always-positive influence on children. In a study of 75 delinquent boys, 25 of whom had been father-absence for 3 of their first 12 years, he failed to find any significant differences between the two groups in any dimensions related to sex-typing. He also investigated the possibility that sex-typing is related to the power distribution in the boy's family: this was also unconfirmed. He did find that, of three boys who fathers were rated 'very warm towards, involved with, and close to son', two engaged in frequent homosexual acts and one was a male prostitute. On the other hand, four boys whose fathers were rates as being 'cold, uninvolved, and emotionally 
distant', none reported any homosexual experiences under sodium amytal. From these data Greenstein draws no conclusions, but suggests extreme caution in treating sex-typing solely from an identification or modeling point of view. Sources of contamination in his study are the fact that the population was asocial in the first place, and the criterion measures used for the fathers were ratings by a social worker.

Santrock (1970) studied a sample of black pre-school children of both sexes. He found that father-absent boys were more feminine, more dependent on adults, and less aggressive than fatherpresent boys. Father-absent boys were found to be significantly less dependent if a father surrogate was available for them. He found that father-absent girls exhibited more feminine behavior than father-present girls, and hypothesized that this was due to their having only a female model, and to the fact that their mothers probably punished male behavior because of their previous failure with males. Santrock suggests further investigation of the influence exerted by older siblings and peers.

Biller (1969) conducted a study which was designed to explore the relation between kindergarten boys' perceptions of father dominance, their fathers' dominance in father- mother interactions, and different aspects of the boys' sex-tying. The findings indicate that a high degree of father dominance in father-mother interaction seems to facilitate the boy's orientation to and preference for his own sex. The boys' perception of father dominance correlates higher with sexrole developments than the actual observed degree of dominance: boys may hold idealized pictures of their fathers which facilitate their development of masculine self-concepts. This suggestion is consonant with that of Mussen and Rutherford (1963), previously cited, that the boy's perception of his father as masculine is more important than the actual masculinity present. Interestingly, Biller also found that fathers who were dominant and masculine, but who were controlling and restrictive of their sons, tended to foster inhibition of their son's masculinity to some degree.

Hetherington (1965) investigated the relationship between dominant parent and sex-role preference of children in 216 families. 108 of the families were classified as father-dominant, and 108 were classified as mother-dominant. Within each classification were 3 sub-classifications for children aged 4-5, 6-8, and 9-11. There were equal numbers of boys and girls.

Hetherington used the IT scale for children, a projective test presumed to indicate sex-role preference, as one of her criterion measures. She found more appropriate sex-role preference in children raised in father-dominant homes than those raised in mother-dominant homes. In girls the difference was insignificant, but in boys the difference was significant at all age levels: motherdominance was related to less masculine self-concepts in boys.

In the same study, Hetherington recorded measures of non-sex-based identification obtain through administration of a specially formulated adjective check list containing 40 descriptive words. Based on this criterion, she found that children tended to be more similar to the dominant parent than to the passive parent. Mother dominance appears to inhibit father-child similarity; boys tended to identify with whoever was dominant. Girls in father-dominant homes identified equally strongly with both parents. Hetherington suggests the possibility that the absence of a dominant father, rather than the presence of a dominant mother, is what is detrimental to boy's development. She also acknowledges consonance of her results with the idea of identification with the aggressor. 
Angrilli (1960) found no relation between masculine identification in pre-school age boys and the sexual identification of their parents. The data he obtained for the parents consisted of their scores on the masculinity-feminity scales of the Strong Vocational Interest Blank and the TermanMiles Aptitude Interest Analysis. The 'corresponding' scores for the boys consisted of ratings by their teachers on an activity checklist and a behavior rating scale. It seems possible that Angrilli's lack of findings was partially caused by the use of such widely diverse assessment methods for the boys and for their parents. A rating by a teacher would seem to represent only an approximation of the true measures, at best.

Mussen (1961) investigated masculine sex-typing in 68 seventeen-year-old males. All subjects were administered the Strong, the TAT, the U.C. Adjustment Inventory, EPPS, and the CPI. In addition, peer ratings and observer ratings were obtained for all Sc. Utilizing these as criterion measures, Mussen found support for the following three hypotheses: (1) Adolescent males with strongly sex-typed interests regard relationships with fathers as favorable and rewarding, whereas boys with more feminine interests are less likely to regard their interactions with their fathers in this way; (2) adolescent males who acquire highly masculine interests will possess more strongly developed personal qualities considered to be characteristic of males in our culture, and that adolescent males who acquire feminine interests will possess qualities considered feminine in our culture; (3) adolescent males who more strongly identified with a male sex-role and would be more stable emotionally and better adjusted socially than low masculine boys.

Biller and Bahm (1971) studied the relationship between the perception of maternal encouragement of masculine behavior and masculinity of self-concept in father-absent and fatherpresent junior high school boys. As their criterion for assessment of masculinity, they employed the Adjective Check list. They found that for males who became father-absent after 5 years of age, masculinity of self-concept was not affected. On the other hand, males who became father-absent before 5 years of age appeared to have experienced interference with masculine identification, and as a result have significantly less masculinity of self-concept. In addition, they found that boys who had become father-absent during the first 5 years of their lives were more likely to have masculine self-concepts if they had perceived their mothers as encouraging aggressive behavior. They concluded that maternal behavior plays a more crucial part in the self-role development of early father-absent boy than it does in later father- absent or father-present boys.

Keller and Murray (1963) conducted a study of the effects of film mediated aggression, similar to Bandura's classic aggressive modeling study. Their subjects were 6-year-old black males, half of whom had been raised in father-absent conditions. The boys were exposed to one of three experimental conditions: they either observed a film of a black male adult behaving aggressively, a film of a black female adult behaving aggressively, or no film at all. After this, the boys were mildly frustrated and observed. The results indicate that both father- present and father-absent boys showed similar levels of aggressive behavior after observing an adult male behaving aggressively, that they showed similar levels of aggression after observing an adult female behaving aggressively, and that they showed similar levels of aggression in the control condition, as well. The level of aggression in both groups was less with the female model than with the male model. Keller and Murray conclude that, in young black males, overt aggressive behavior 'may be more directly related to the role of the mother than to the presence of or absence of the father' (p.220). However, they also speculate that father-absence might have subtle effects on the male self-concept which are not necessarily apparent in this measure of overt behavior. 
In addition to the research discussed in the preceding pages, several other studies have been conducted in this area (Altus, 1958: Biller, 1971; Blanchard and Biller, 1971: Herzog and Sudia, 1973: Leonard, 1966; Mimbauer, 1969: Nelson and Maccoby, 1966). In attempting to draw conclusions from what has been done, it is difficult not to invoke the usual plea that 'more research must be done before any conclusions can be drawn'. There do, however, seem to be some reasonable assertions which can be made.

First of all, it does seem probable that there is a relationship between male children's perception of their father's masculinity and the degree of male sex-role preference they exhibit. This seems probable on the theoretical grounds of learning and modeling, as well as being evidenced in several significant studies. A few of the studies yielded findings which conflict with this idea: methodological considerations might be at fault, however.

Secondly, it appears likely that that nurturant parental models are imitated more than punitive parents: this is true not just in sex-role development, but in other developmental learning, as well.

It also seems clear that boys who are deprived of a father model are more seriously disadvantaged than are girls who face this same deprivation; while there is no clear evidence of girls being affected negatively, there is quite a bit of indication that boys suffer through inhibition of aggression and less masculinity of self-concept. While there are also studies the results of which conflict with these, it is possible that the different populations from which the samples were drawn (black inner city vs. white suburban) might account for some of the difference.

The most important methodological consideration in the planning of new research appears to be the strictest possible control for extraneous variables. Biller (1967) has mentioned that ' ... most of the studies done concerning masculine development have methodological shortcomings' (p.264); most such studies take no account of '... certain variables other than parent-child relations which might influence masculine development.' (p.265). Biller suggests that individual differences in intelligence or physique might be taken into account when drawing samples, for example. He also proposes that many times ' ... the sources of parental behavior and of boys masculinity are not independent leading to problems in interpretation' (p.265).

In closing this section, it is interesting to note how close to apparent fact Kagan (1958) was when he hypothesized three conditions necessary for the establishment of an optimally strong masculine identification in boys: the father must be perceived as nurturant to the child; he must be perceived as being in command of desired goals and as being competent in tasks which the child regards as important; and he must be perceived in a way exhibiting similarity between himself and his child on the basis of external attributes. So far, research has not discredited any of these speculations.

\section{Paternal Determinants of General Personality Functioning}

As mentioned earlier, the role of the father in his child's general personality functioning has been investigated primarily in terms of correlations between aspects of his behavior and his children's behavior. While such relationships can lead to partial understanding of the family patterns involved, they are only a small first step toward understanding the etiology of maladaptive behavior. 
Areas which have been reported on with respect to this topic range from such normal variations of personality traits as different attitudes toward the opposite sex, to consideration of less widely accepted behavior such as homosexuality, to familial patterns found in connection with a social, behavior and schizophrenia. While there is overlap within the articles themselves, in some cases, the progression in this section will generally be from lesser to greater disturbance.

Hetherington $(1972,1973)$ has studied the effects of two kinds of father-absence upon first born adolescent girls between the age of 13 and 17. Of her sample of 72, one third came from families in which the parents lived together, one third came from families in which the parents were divorced and the children had minimal contact with the father, and one third came from families in which the father had died. None of the girls had brothers, and there were no other males living in the households of the divorcees or the widows.

The two experimental conditions involved a 15 minutes interview with either a male or a female, while observers recorded the interactions seen through one-way mirrors. When the girls first entered the room, they had a choice of three chairs: they could select one directly across the desk from the interviewer, another across the desk and about 3 feet down from the interviewer was seated, or a third at the end of the desk and at right angles to the interviewer position.

When the interviewer was male, however, there were significant differences in their behavior. Eight of the 12 girls whose parents lived together chose the middle seat, eight of the 12 girls whose parents were divorced chose the chair closest to the interviewer, and ten of the 12 girls whose fathers had died chose the chair farthest from the interviewer. The girls from intact families generally sat relaxed and comfortable for the 15 minutes. The girls whose parents were divorced generally were much more forward and smiled more often. The girls whose fathers had died generally sat stiffly upright, avoided eye contact, and did not smile.

Additional data were gathered via structured interviews which explored the girls' feelings about themselves, interviews with their mothers about their interaction and behavior, and a battery of personality tests administered to both the girls and their mothers. It was found that girls separated from their fathers prior to age 5 were more affected than those separated later. Separation by death and separation by divorce both correspond to insecurity around male peers and adults, but this was manifested in different ways. Girls whose parents were divorced reported more heterosexual activity than the other groups, and girls whose fathers had died reported late starts on dating and appeared to be sexually inhibited. From this Hetherington concludes that the effects of father-absence on daughters appear during adolescence and manifest themselves mainly as an inability to interact appropriately with males, rather than in other deviation from appropriate sex-typing or in interactions with females. She proposes that for both groups of fatherless girls the lack of opportunity for constructive interaction with a loving, attentive father results in apprehension and inadequate skills in relating to males.

The different views of males held by the divorcee daughters and the widow daughters might be partially explained as being due to the circumstances of the separation. The daughter of the divorcee may view her mother's separated life as unsatisfying, and feel that happiness requires a man. If she has a hostile image of her absent father, Hetherington proposes, it may lead to ambivalence, apprehensiveness, and ineptness in her pursuit of this goal. Conversely, daughters of widows may have grandiose images of their fathers. They may feel that no other male can compare favorably with him, and so may reject the idea of interpersonal relations with males. 
Hetherington points out that while research on males has found that the effects of fatherabsence tend to appear early and decrease with age, she found that the effects on girls remain latent until adolescence. She speculates that the ' ... future work on the effects of father absence on females might find its most important evidence in the lives of mature women' (p.52).

Hetherington's study seems to be superior to most of the others discussed thus far. She has taken steps to control for extraneous variables, as well as attempting to assess criterion variables from different points of view so as to arrive at truer measures. It would certainly be of interest to compare the results of a study done equally as thoroughly with males to those of the more abbreviated earlier studies discussed in the first section.

Reuter and Biller (1973) studied the relation between perceived paternal nurturance and availability to personality adjustment in college males. 172 subjects were administered the CPI and the ACL, as well as being asked to rate the degree of nurturance availability they had perceived their fathers as providing when they were young.

Their findings indicate that the most well-adjusted men were those who had perceived their fathers as highly nurturant and highly available, highly nurturant and moderately available, or moderately nurturant and highly available. On the other hand, the two groups which suffered most in terms of low personal adjustment were those who had perceived their fathers as highly available but low on nurturance, and those who had perceived their fathers as highly nurturant but low on availability. From these results Reuter and Biller reasoned that if fathers are constantly available but pay little attention to the needs of their sons, then they are a detriment to their sons, who are consequently more likely to develop insecurities. At the same time, fathers who are highly nurturant, but never available, seem to cause frustration through lack of contact, and this is also related to inadequate adjustment in their sons.

Reuter and Biller point out that it may be the case that a boy with a non-nurturant father is better off if the father is less available, for their results indicate that these boys made better adjustment than those with available, non-nurturant fathers. This is congruent with the earlier work of Biller (1971), who found some evidence that father-absent boys may make better personality adjustments than boys with passive, ineffectual fathers.

This study by Reuter and Biller appears to be a logical test of the hypothesis that a boy's perception of his father has a direct bearing on his development. It would be of interest to obtain objective ratings of the same boys' fathers' nurturance and availability (an impossibility) and see if they correlated significantly lower with the boys' adjustment levels than did the boys' perceptions.

Trunnell (1968) put forth 3 general hypotheses he had formulated on the basis of research he had previously conducted. The first 'hypothesis' states that '... paternal absence has a significant, though ill-defined, effect on normal child development - it seems to correlate both with form and severity of psychopathology when manifested in young children. The younger the child is at the time of paternal absence, the more severe is the psychopathology manifested' (p.180). However, as an exception to this rule, Trunnell did believe that when deprivation occurs during the first year of the child's life and the paternal object is reinstated before the child develops the capacity for object distinction (12 to 18 months), there will probably be fewer or no negative effects. If the father figures is not replaced, it may lead to poor ego differentiation and an intensified tie to the mother, as well as deviances in stability of sex identity in the male child. 
The second general hypothesis indicates that if absence occurs during the period from 1 to I $1 / 2$ • years, the child may later manifest persistent stereotyped behavior that originally occurred when the father was present. If absence occurs between 3 and 5 in the male child, hyperactive, destructive behavior may be seen. If absence occurs between 3 and 5 years in the female child, blatantly awkward attempts at involving males will occur.

Trunnel's third hypothesis states that paternal absence is never a sole force in personality development or in manifest psychopathology. Equally important are the child's general environment, the availability of father surrogates, and the personality of the mother.

Based on the classification and analysis of information contained in the hospital charts of 252 children who had been seen diagnostically, he concludes that the hypothesis are supported, but that the limitations of retrospective study necessitate additional research into types and significances of paternal deprivation syndromes.

In spite of the speculative nature Trunnell's article, and the broadness of his 'hypotheses', most of the points he made have been in some form in more recent research. Particularly interesting is his finding, similar to that of Hetherington (1972, 1973), that girls who become father-absent at ages 3 to 5 (his father-absence was not due to death) will develop blatantly awkward attempts at involving males in their lives. Also, his findings regarding early onset related to problem severity seem consonant with several of the sex-role studies. Needless to say, it can hardly be disputed that other variables besides paternal deprivation come into play in shaping the deprived child's personality.

Mischel (1961) studied 8 and 9-year-old West Indian children in terms of their preference for large delayed or small immediate rewards. Father-absent children showed a stronger preference for immediate gratification than did father-present children. Biller (1969) speculates from these findings that if the father-absent child has difficulty learning how to delay gratification, he may find it difficult to persist in frustrating situations or in meeting long-term responsibilities. It is interesting to note, however, that when Mischel (1961) used 11 to 14-year olds, he discovered no association between father-absence and preference for immediate gratification. Perhaps, ' ... as the father-absent child grows older, his wider experience helps him to develop a trust of others beyond those in his immediate family.

Biller (1970) reviewed the literature pertaining to paternal deprivation as it affects personality development of the male child, and concluded that the effects of father absence on personality development cannot be considered in isolation from other factors. These include timing and length of father absence, social milieu, availability of a surrogate, and especially individual differences in maternal behavior. He states that the general implication from studies which are available is that ' ... the rates of paternal absence are higher for children with emotional problems than for children in the general population' (p.192).

Kaye et al (1967) investigated the parental relationships of 24 homosexual female patients compared to those of 24 non-homosexual female patients. They found that, in general, the fathers of the homosexual women were less dominant in major decisions, and that the mothers often regarded the father as inferior. The fathers appeared to be more seductive and dominating (of the daughter) than were the fathers of the non-homosexuals. Also, the fathers of the homosexuals were far more possessive of their daughters, and were often disapproving and belittling of their 
boyfriends and girlfriends. The fathers appeared to have attempted to ally the girls against their mothers by babying them, being overconcerned for them, and in general exploiting them to fulfill their own needs. This placed the daughters in the position of having someone as a model the father did not want them to emulate (their mothers). Kaye concludes that ' ... homosexuality in women, rather than being a conscious volitional preference, is a massive adaptational response to a crippling inhibition of normal heterosexual development' (p.633).

Nash and Hayes (1965) conducted a pilot study concerning the parental relationships of male homosexual prisoners. They divided their sample in 'passive' and 'active' homosexuals; the 'passive' homosexuals preferred a passive female role in sexual relationships, while the 'active' homosexuals preferred a more aggressive male role. They found that more 'passive' than 'active' homosexuals did not get along well with their fathers, thought their fathers were neglectful of them, thought their fathers did not love them, disliked their fathers, had been afraid of their fathers as children, liked their mothers better than their fathers, had had a desire for love and affection from their mothers at age 12, admired their mothers and wished to emulate them, thought that their parents would have preferred them to be a girl, and recalled having themselves wished that they had been born a girl.

Nash and Hayes conclude that 'active' homosexuals have had a partial identification with their fathers which enables them to identify with certain aspects of the male role, such as the aggressive, dominant behavior considered appropriate in social situations. 'Passive' homosexuals, they speculate, do not identify at all with their fathers.

Several other studies have indicated that paternal deprivation or ineffectual fathering of male children can lead to the development of homosexuality or some difficulties in heterosexual relationships. West (1959) and O'Connor (1964) discovered that homosexual males often had histories of extended father-absence during childhood. 'Difficulty in forming lasting heterosexual relationships often appears to be linked to paternal deprivation' (Biller, 1971, p.71). Father's death prior to the age of 12 appears to be related to a high rate of marriage difficulty later on (Jacobson and Ryder, 1969). 'Inadequate paternal care combined with an intense close-binding mother-child relationship has been seen to be particularly likely to lead to the development of homosexuality in males' (Biller, 1971).

Numerous studies have linked paternal deprivation or inadequate fathering to delinquent tendencies in the boys (Bicker, 1962; Glueck and Glueck, 1950; Gregory, 1965; McCord, McCord and Thurber, 1962; Medinnus, 1965; Nye, 1958; Siegman, 1966). Siegman (1966). Siegman (1966) attributes such results largely to the paternally deprived male's overcompensation in reaction to basic female identification by exhibiting 'exaggerated masculine behavior'. He suggests that fatherabsent circumstances may lead boys to confuse 'being good' with being 'feminine': to be masculine they must be 'bad'. 'This "masculine protest" theory of anti-social behavior,' Siegman says, 'leads to the prediction that all factors which tend to produce strong identification with the mother, and failure of early identification with the father, also tend to produce anti-social behavior' (p.71).

According to the material reviewed by Coleman (1972), the father of the child with the anti-social personality is generally highly successful, striving, critical, distant, and is often fear inspiring to his son. In the family itself, the parents may maintain the illusion of a 'happy family' by pretending the difficulties don't exist. Consequently, the children learn that appearances are more important than reality. While the son cannot hope to emulate the 
successful and awe-inspiring father, he does learn well from him the importance of covering up reality by putting up a facade for others. The father may also provide a contradictory influence by telling his sons of the necessity for responsibility, honesty, and respect of others, while the father himself is deceitful and manipulative.

In discussing the related aspects of delinquency, Coleman points to the father's rejection of his son, and his use of physically punitive methods of discipline. He also points to evidence that the fathers of delinquents often have abandoned their role in child rearing altogether. Among such fathers, there is a high incidence of such sociopathic traits as alcoholism, anti-social attitudes, failure to provide, and frequent unnecessary absence from home.

Anderson (1968) studied 43 male adolescent delinquents to investigate the relation between paternal deprivation and delinquency. He suggests that effective fathering is of vital importance to the growing boy after age 4 as an experience which promotes maturation and social adaptation, and that fathering is a 'growth factor' to which the boy is particularly susceptible during the 4 to 7 year period. His hypothesis is that boys alienated from or deprived of their fathers during this time period do not resolve their Oedipal conflicts, nor do they, identify adequately, and as a result there is a deficiency of superego function. In this way Anderson partially accounts for the higher proportion of father-absent boys among delinquent populations.

Criticism of Anderson's work consists mainly of the fact that it is based entirely on inferences with no objective analysis. In addition, although he emphasized the importance of 'effective fathering', there is no discussion of what component variables go into effective fathering.

Garmezy, Clark and Stockner (1961) studied perception of parental child rearing attitudes reported by schizophrenic and normal patients. One third of their sample consisted of poor premorbid schizophrenics, one third of good premorbid schizophrenics, and one third of nonpsychiatric hospital patients. All subjects were asked to respond to a 75-item questionnaire about child rearing as they felt their parents would have responded when the subjects. were younger.

There was considerable indication that the childhoods of the poor premorbids were characterized by maternal dominance, whereas the childhoods of good premorbids and normals were characterized by paternal dominance. The 'poors' perceived overprotection by mothers. One half of the poors felt that they had been neglected by their fathers, while one third of the goods and one sixth of the normals felt this way. They conclude that the attention paid by the father is an important factor in the background of schizophrenia.

Coleman (1972), in a discussion of the findings regarding fathers of schizophrenic females, reports that their fathers are often inadequate, indifferent, passive, detached, humorless, and insensitive to the needs of others.

Fleck et al (1963) studied differential parental relationships of male and female schizophrenics, based on a small sample of 17 families. They found that fathers of the female schizophrenics evidenced paranoid tendencies, narcissism, and doubts about their masculinity. Unsatisfied with their wives, they turned seductively to their daughters, placing their daughters in a position of conflict. For them to seek their father's love 'they must differentiate themselves from their mothers, whom their fathers find so unsatisfactory, rather than emulating a woman whom father loves' (p. 3). Fathers of the male schizophrenics were generally passive and ineffectual, 
offering poor role models for their sons to emulate. Many of them behaved more like sons than husbands, taking rivalrous rather than paternal roles towards their sons.

In addition to the relationship described in this section, paternal factors have been linked to a host of other 'abnormalities', especially in the boys. These abnormalities include suicide attempts (Gay and Tonge, 1967; Robins, Schmidt, and O'Neal, (1957), depression (Hayworth, 1964; Hill and Price, 1967; Keeler, 1954), anxiety (Koch, 1951), anxiety about sex (Stephens, 1961) and low selfesteem (Rosenberg 1965). With a few exceptions, the methodological pitfalls in this whole area of research are many. However, in spite of all these flaws, there appears to be enough evidence to indicate, in a general way, the importance of paternal variables in the personality development of children, with particular reference to the boys. Most of the personality problems appear to be related to the difficulties involved in the sex-role development of children with inadequate or no fathers. A good deal of well- controlled research will have to be conducted, anyhow, before we can arrive at a clear understanding of the relationships indicated so far.

\section{Paternal Factors Influencing Cognitive Development in Children}

The predominant theme of research in this area has been the effect of father absence/presence on later IQ/achievement of children. The findings in these studies have the advantage of being somewhat more consistent than in some of the other research.

An early study in this area was conducted by Carlsmith (1964) on the scholastic aptitude of Harvard students relative to father absence/presence. She explored the differential verbalquantitative abilities of males based on the father condition. Normally, males have higher quantitative scores than verbal scores on measures of aptitude (in this case the SAT). Of males whose fathers had been away from home for some substantial length of time because of military service, she found verbal scores nearly equal to, or higher than, the quantitative scores.

Carlsmith's conclusions are that early and prolonged separation from the father results in relatively greater ability in verbal skills than in quantitative skills, whereas no separation results in relatively greater quantitative skills. Boys who achieve a more 'feminine' pattern of aptitudes generally report that during childhood their father was away for 1 to 5 years, that they almost never talked about personal problems with their fathers, that they were often fearful of their fathers, and that they were punished almost exclusively by their mothers.

Landy, Rosenberg and Sutton-Smith (1969) studied cognitive development in girls whose fathers had worked nights during various periods in their childhoods. According to the quantitative scores on the American College Entrance examination, those girls whose fathers had worked nights during either the first four years of their lives, or the years 5 to 9, scored significantly lower than those girls whose fathers did not work nights. The authors conclude that the first 9 years are collectively a 'critical period' for the development of quantitative skills in females. They also point out that Jong-term night shift work by fathers can be considered to be a point on the father absence/presence continuum.

Sutton-Smith, Rosenberg and Landy (1968) studied 295 children and found that father absence correlated with a lower cognitive ability level. They found that only girls are more strongly affected cognitively than are only boys, and that there is an interaction effect due to siblings in that father-absent girls develop significantly better cognitively if there is an older brother in the family. 
While the sample in the study is large, there is too little control of other variables (such as IQ of mother) to allow much speculation as to causality.

Solomon, Hirsch, Sheinfield and Jackson (1972) found that in ghetto children, father absence had no significant effect on the general academic achievement of elementary school children. They acknowledge that these findings may not generalize to other populations, however.

Santrock (1972) correlated father absence/presence with both third and sixth grade intelligence measures for 343 high school boys and girls. Father absence was analyzed by age at onset, 0-2, 3-5, 6-9, 10-11, 12-13, and also by cause of separation, whether death or divorce. He found that father absence, by either separation or divorce, had its most detrimental effect when it occurred during the first two years of children's lives for males and females. Father absence due to death was most detrimental when it occurred in the 6-9 year span for boys, but negative effects on girls were not related to their age when their father died. Boys deprived of fathers were consistently lower in cognitive development than either father-absence girls or father-present boys. Remarriage of divorced mothers, if it occurred within the boy's first 5 years, had a positive effect on his cognitive development compared to boys whose mothers did not marry.

Radin (1972) conducted one of the few studies of variable present in living fathers which relate to intellectual functioning. Her work was done with 4-year-old boys: she conducted interviews which were taped with both fathers and sons present. Based on the tapes and her observations, she rated fathers according to nurturant behavior displayed or restrictive behavior displayed.

Behavior termed nurturant included verbal reinforcement, physical reinforcement, consulting with the child, ordering with explanation, retroactive limit setting, preventive warning, promising to reinforce, responding to the child's needs, communication affection, initiating and motivating behavior in the child, sharing, and requesting information from the child. Behavior termed restrictive included ordering without explanation, threatening, using aversive verbal stimuli, and using aversive physical stimuli.

After obtaining measures of the boys' intelligence, she found that there is a significant positive correlation between IQ and observed paternal nurturance. The aspect of paternal behavior which correlated the highest with son's IQ was 'asking information of the child', suggesting that such stimulation fosters the child's use of and development of his own cognitive capacities.

Radin speculates that '... perhaps identification with the father is fostered by nurturant behavior; the son is motivated to incorporate the fathers' ideas into his own cognitive structure, as well as to imitate his problem solving methods' (p.358). If this were so, ' ... restrictive paternal behavior could be said to interfere with the identification process, and therefore with the intellectual functioning of the young boy' (p.358).

Another feasible alternative suggested by Radin is that ' ... paternal nurturance suggests to the child that interaction with the environment is likely to be rewarding (p. 358). This facilitates exploratory behavior and consequent cognitive exercise by the boy. In the case of the restrictive father, the boy may develop fear of interacting with the environment; this could be seen to create within the child a disinclination to explore, thus hindering intellectual growth. 
Another study by Radin (1973) replicated the 1972 findings, thus indicating the stability of the relationship between paternal nurturance and measures of intellectual functioning in boys. She further discovered that father nurturance found most important components to be use of reinforcement, consultation, and sensitivity to the son and to his intellectual performance. She also found a significant relation to such paternal behavior as reading to the child and teaching him to count and read. These practices, she reasons, may have helped in two senses: first of all, it gave the child lessons and practice, but equally importantly, it allowed him to see his father involved in 'academic' behavior and thus may have helped him to see such behavior as more masculine, acceptable, and important.

Several other researchers have investigated the relationship between paternal factors and varied measures of cognitive functioning in children (Kimbal, 1952; Maxwell, 1961; Mutimer, Laughlin and Powell, 1966; and Shaw \& White, 1965). On the basis of all these studies, one can, perhaps, tentatively conclude that father-absent children score lower on various cognitive measures than father-present children do, and that father-absent boys are at more of a disadvantage than father-absent girls. The same can perhaps be said about children who receive inadequate fathering. It must be noted, however, that a few studies have indicated the possibility that the absence of a father and the consequent close relationship with the mother may indeed by the cause of superior academic achievement in many cases (Albert, 1969; Gregory, 1965; Hilgard, Newman and Fisk, 1960; and Nelson and Maccoby, 1966). It remains for future research to clearly determine when father absence is detrimental and when helpful to the cognitive functioning of children especially boys.

\section{Other Developmental Correlates of Paternal Behavior}

Several other research areas in the literature include paternal influences on children's conscience development, effects of paternal punitiveness, factor analytic studies of fathers' personality characteristics, and children's perception of father. In most cases, there is overlap with one of the areas already discussed, but the articles place their emphasis on different topics.

Hoffman (1971) investigated male and female conscience development as related to paternal variables. He discovered that the absence of a father has adverse effects on male conscience development, but not on that of females. Father-absent boys scored lower than father-present boys on measures of internal moral judgment, guilt reaction to transgressions, acceptance of blame, moral values, and conformity to rules. Weak identification or lack of identification with the father was also seen to be related to some degree to inadequate conscience development in boys. From this Hoffman infers that some but not all effects of father absence are attributable to the lack of a paternal model.

Hoffman (1960) studied power assertion by the parents and the effect it has on children. He basically discovered some significant differences between middle- and lower-class fathers with respect to Unqualified Power Assertion (UPA) with the latter being higher on this measure. These differences were not present between their wives. Hoffman also found that the fathers' authoritarianism and power needs correlated with their use of UPA. When this was directed at their wives, the wives in turn tended to use UPA with their children who constituted a 'safe' target. This was seen in both middle and lower class mothers, and was interpreted as representing the father's indirect role in punitive modeling. 
Schvaneveldt, Fryer and Ostler (1970) attempted to assess the means by which young children differentiate between 'good' and 'bad' in their perceptions of their parents. They interviewed 86 nursery school children of both sexes, and found no difference between the proportion of girls and that of boys who perceived their parents as 'good'. They did find, among children who saw bad aspects of their parents, that there were differences between the sexes as to what constituted 'goodness' or 'badness'. Girls, more than boys, saw their fathers as 'good' if they performed appropriate social tasks such as working and taking care of mother, and if he displayed affection to others. Girls viewed the father as the nurturant parent. Boys, more than girls, saw father as 'good' if he engaged in recreation with them, read stories to them, or talked and sang to them. Boys viewed the mother as the nurturant parent. Both sexes see the 'bad' father as the disciplinarian, who spanked them, slapped them or sent them to bed.

Dielman, Barton and Cattell (1973) administered child rearing questionnaires to 331 mothers and 307 fathers of junior high school children. After factor analysis of the information they obtained, 8 factors were extracted which appeared, with different weightings, in the fathers. The 8 factors consisted of the following: High use of reward, high use of physical punishment, promotion of independence, preference for younger children, strict discipline, low use of reasoning, belief that wife is responsible for child rearing and dissatisfaction with home life.

In preliminary analysis of father factors related to children's personality factors, they found that high use of reward by fathers is related to a child behavior problem factor labelled 'acting out', tension and apprehension in children. Also, the father's dissatisfaction with home life was found to be related to the child's personality dimension of 'toughmindedness'. Pederson and Robson (1969) attempted a more practical investigation of father factors in child rearing by making two visits to the homes of parents of young babies, once when they were 8 months old and again when they were $91 / 2$ months old. Based on extensive interviews with the mothers, they were able to delineate 8 variables in the father's paternal behavior. The first is caretaking, which represents the father taking a part in the actual physical caretaking. Next is investment, which overlaps with caretaking but includes emotional involvement and positive affect. Time spent on play is the third variable; reported amounts ranged from 45 minutes to 26 hours per week. Irritability level comes next representing the father's reactivity to the baby's fussiness and crying. Fifth is apprehension over well-being, seen more often with female babies. Sixth is authoritarian control, in terms of restrictiveness/permissiveness. Next is stimulation level of play with baby, ranging from cautious to excitatory. Surprisingly, no differences were found between male and female babies. The final variable is overall availability, the average hours per week that the father is home while the baby is awake. The mean was 26 hours, with a range from 5 to 47 hours.

After compiling ratings on these variables, they obtained measures of attachment in terms of the baby's age at onset, and intensity of greeting behavior toward the father. Correlating this with the 8 father factors, they arrived at 5 significant correlations, 3 positive and 2 negative.

Attachment behavior in the male baby was positively correlated to caretaking, investment, and stimulation level of play. Irritability level was negatively correlated to attachment in the male child, and apprehension over well-being was negatively correlated to attachment in the female child. The authors draw no conclusions, but suggest further research.

While the analysis is interesting, one must wonder how much validity to ascribe to the mothers' ratings of the fathers, especially in light of the findings of Eron et al. (1961) that such 
ratings are subject to a high degree of error. Also, the criterion variable of greeting behavior in the infant is undoubtedly influenced by variables other than behavior of the father. It would be interesting to correlate these subjectively defined father traits with Dielman's factors, and possibly gain a better understanding of both sets of variables.

\section{Concluding Remarks}

Bigner (1970) suggests that the father should take a more active role in child rearing to offset, somewhat, the cultural mother-centeredness of American families. He also proposes that both parents and teachers make an attempt to increase children's understanding of just what the father does during his working hours, to help the child develop a concept of this aspect of the father's role. This could be done, he says, via field trips whereby children see their fathers actively involved in their work. He further suggests that fathers should take a more positive role in sex education, community programs, preschool and elementary teaching, and that older male siblings and peers take an active role in fathering behavior for the benefit of father-deprived children. His children should become a much more important part of every father's life, Bigner feels. However, in the context of contemporary American society, it would take quite a campaign effort to produce these desired results.

Almost all of the research attributing development of the male sex-role to the availability of a nurturant paternal model were conducted in American culture. Mead (1939) points out that Samoan fathers have a very slight role in their children's lives; that the upbringing is performed by an army of relatives, with constantly changing constituencies within households. By reason of the research on masculine self concept, males raised in such a transient setting with no stable father figure should be expected to be somewhat 'feminine' or insecure'. And yet, by her report, this is not the case. Although no cross-cultural comparisons have been conducted in terms of experimental studies, it is likely that concern about rigidly developed sex-roles is a function of cultural expectation.

Evidence from animal studies would lead to the belief that sex-typed behavior does have hereditary components, however. Mitchell (1969) discusses the apparent existence of identification in monkeys. He cites evidence showing that infant monkeys who 'identify' with a dominant male have a good chance of becoming a dominant male themselves. Other primate studies have found that paternalistic protective behavior increases when a mother dies or is separated from her infant; the father protects the infant from aggression within the group and may even 'adopt' and carry the infant.

By virtue of these animal studies, it should be clear that the cultural stereotype which holds that the mother should be the sole agent in child rearing is not biologically defensible. This image is fading somewhat, fortunately, as increasing research points to the importance of the father's role in child development.

It must be noted, however, that a good deal of research conducted so far in this area suffers from a number of methodological problems. Often paternal behavior is assessed through reports by mothers or children; the sources of information concerning fathers and children are frequently the same; many studies are correlational, thereby making it difficult to establish a cause-effect relationship; in several cases, father-absence is treated in a vague and general way, without specifying type, length, and age of onset; 'potentially important variables such as sex of child, IQ, 
socio-cultural background, birth order, sibling distribution and availability of father surrogates are often not taken into account, either in subject matching or in data analysis' (Biller, 1971, p. 120); mother's influence in a paternally deprived child's life has also been relatively neglected. All of these factors will have to be considered in future research before any solid conclusions can be drawn. Direct observations of family interactions and longitudinal studies will be especially helpful in clearing the fog.

\section{References}

Ahnsen, A.: 'Nature and Behaviour of Pure Eidetics'. Unpublished manuscript. Eidetic Analysis Institute, Yonkers, N. Y., 1970.

Ahnsen, A.: Eidetic Parents Test and Analysis. New York: Brandon House, Inc., 1972. Albert, R. S.: Early Cognitive Development Among the Gifted. Paper presented at the meeting of the Western Psychological Association, Vancouver, British Columbia, Canada, June 1969.

Altus, W. D.: 'The Broken Home and Factors of Adjustment.' Psychological Reports, 1958, 4,477.

Anderson, R.: 'Where's Dad?: Paternal Deprivation and Delinquency.' Archives of General Psychiatry, 1968, 18, 641-649.

Angrilli, A.: 'The Psychosexual Identification of Preschool Boys.' Journal of Genetic Psychology, 1960, 97, 329-340.

Bieber, I.: Homosexuality. Basic Books: New York, 1962. Signer, J.: 'Fathering: Research and Practice Implications.' Family Coordinator, 1970, 19, 357-362.

Biller, H.: 'Masculine Development: An Integrative Review': Merrill-Palmer Quarterly, 1967, 13(4), 253-294.

Biller, H.: Father Dominance and Sex-Role Development in Kindergarten Aged Boys. Developmental Psychology, 1970, 2(2), 87-94.

Biller, H.: 'Father Absence and the Personality Development of the Male Child.' Developmental Psychology, 1970, 2(2), 181-201.

Biller, H.: Father, Child and Sex-Role. Massachusetts: Heath Lexington Booke, 1971. Biller, H. and Bahm, R.: Father 'Absence, Perceived Maternal Behaviour, and Masculinity of. SelfConcept Among Junior High School Boys.' Developmental Psychology, 1971, 4(2), 178181.

Biller, H. and Weiss, S.: The Father-Daughter Relationship and the Personality Development of the Female, Journal of Genetic Psychology, 1970, 116, 79-93.

Blanchard, R. W. and Biller, H.B.: Father Availability and Academic Performance Among Thirdgrade Boys. Developmental Psychology, 1971-4, 301-305.

Carlsmith, L.: Effect of Early Father Absence on Scholastic Aptitude, Harvard Educational Review, 1964, 34, 3-21.

Coleman, J.: Abnormal Psychology and Modern Life. Scott, Foresman and Co. Illinois, 1972.

Dielman, T., Barton, K. and Cattell, R.: Cross-validational Evidence on the Structure of Parental Reports of Child Rearing Practices. Journal of Social Psychology, 1973, 90, 243-250. Eron, L., Banta, T., Valder, L. and Laulicht, J.: Comparison of Data Obtained from Others and Fathers on Child Rearing Practices and their Relation to Child Aggression. Child Development, 1961, 32, 457-473.

Fleck, S., Lidz, T. and Cornelison, A.: Comparison of Parent-child Relationships of Male and Female Schizophrenic Patients. Archives of General Psychiatry, 1963, 8, 1-7.

Garmezy, N., Clarke, A. and Stockner, C.: Child Rearing Attitudes of Mothers and Fathers as Reported by Schizophrenic and Normal Patients. Journal of Abnormal and Social Psychology, 1961, 63(1), 176-182. 
Gay, M. J. and Tonge, W. L.: The Late Effects of Loss of Parents in Childhood British Journal of Psychiatry, 1967, 113, 753-759.

Gluecks, S. and Glueck, E.: Unravelling Juvenile Delinquency. New York: Commonwealth Fund, 1950.

Greenstein, J.: Father Characteristics and Sex-typing. Journal of Personality and Social Psychology, 1969, 3(3), 271-277.

Gregory, I.: Anterospective Data Following Childhood Loss of a Parent: I. Delinquency and High School Dropout. Archives of General Psychiatry. 1963, 13, 99-109.

Gregory, I.: Anterospective Data Following Childhood Loss of a Parent: II. Pathology, Performance, and Potential Among College Students. Archives of General Psychiatry, 1965, 13, 110-120.

Haworth, M. R.: Parental Loss in Children as Reflected in Projective Responses. Journal of Projective Techniques, 1964, 28, 31-35.

Herzog, E. and Eudia, C. E.: Children in Fatherless Families. In B. M. Caldwell and H. N. Ricciuti (Eds.)., Review of Child Development Research, Vol. 3, The University of Chicago, Press, 1973.

Hilgard, J. R., Neuman, M. F. and Fisk, F.: Strength of Adult Ego Following Bereavement. American Journal of Orthopsychiatry, 1960, 30, 788-798.

Hetheringtone, E.: A Developmental Study of the Effects of Sex of the Dominant Parent on Sexrole Preference, Identification, and Imitation in Children. Journal of Personality and Social Psychology, 1965,2, 188-194.

Hetherington, E. and Frankie, G.: Effects of Parental Dominance, Warmth, and Conflict on Imitation in Children. Journal of Personality and Social Psychology, 1967, 6(2), 119-125. Hetherington, E.: Girls without Fathers. Psychology Today, Feb., 1973, 47-52.

Hetherington, E.: Effects of Father Absence on Personality in Adolescent Daughters. Developmental Psychology, 1972, 2(3), 313-326.

Hoffman, H.: Father Absence and Conscience Development. Developmental Psychology, 1971, 4(3), 400-406.

Hoffman, M.: Power Assertion by the Parent and its Impact on the Child. Child Development, 1960, 31, 129-143.

Jacobson, G. and Ryder, R. G.: Parental Loss and Some Characteristics of the Early Marriage Relationship. American Journal of Orthopsychiatry, 1969, 39, 770-787.

Johnson, M.: Sex-role Learning in the Nuclear Family. Child Development, 1963, 34, 319-333.

Kagan, J.: The Concept of Identification. Psychological Review, 1958, 65, 296-305. Kaye, H.: Homosexuality in Women. Archives of General Psychiatry, 1967, 17, 626-634.

Keller, P. and Murray, E.: Imitative Aggression with Adult Male and Female Models in Father Present Negro Boys. Journal of Genetic Psychology, 1973, 122, 217-22.

Keeler, W. R.: Children's Reaction to the Death of a Parent. In P.H. Hoch and J. Zubin (Eds.), Depression. New York: Grune, 1954, 109-120.

Kimball, B.: the Sentence Completion Technique in a Study of Scholastic Underachievement. Journal of Consulting Psychology, 1952, 16, 353-358.

Koch, M. B.: Anxiety in Preschool Children from Broken Homes. Merrill-Palmer Quarterly, 1961, I, 225-231.

Landy, F., Rosenberg B. and Sutton-Smith, B.: The Effect of Limited Father Absence on Cognitive Development. Child Development, 1969, 40, 941-944.

Leonard, M. R.: Fathers and Daughters. International Journal of Psychoanalysis, 1966, 47, 325333.

Maxwell, A. E.: Discrepancies Between the Pattern of Abilities for Normal and Neurotic Children. Journal of Mental Science, 1961, 107, 300-307. 
McCord, J., McCord, M. and Thurber, E.: Some Effects of Paternal Absence on Male Children. Journal of Abnormal and Social Psychology, 1962, 64, 361-369.

Mead, M.: From the South Seas. Wm. Morrow and Co., New York, 1939.

Medinnus, G. N.: Delinquents' Perception of their Parents. Journal of Consulting Psychology, 1965, 29, 5-19.

Meerloo, J. M.: The Psychological Role of the Father. Child and Family, Spring, 1968, 102-114.

Mischel, W.: Father Absence and Delay of Gratification: Cross-cultural Comparisons. Journal of Abnormal and Social Psychology, 1961 63(1), 116-124.

Mitchell, G.: Paternalistic Behaviour in Primates, Psycholigical Bulletin, 1969, 71(6), 399-417. Mussen, P.: Some Antecedents and Consequents of Masculine Sex-typing in Adolescent Boys. Psychological Monographs, 1961, 75(2), 1-24.

Mussen, P. and Rutherford, E.: Parent-child Relations and Parental Personality in Relation to Young Children's Sex-role Preferences. Child Development, 1963, 34, 589-607.

Mumbauer, C. C.: Resistance to Temptations in Young Negro Children in Relation to Sex of the Subject, Sex of the Experimenter, and Father Absence or Presence. DARCEE Papers and Reports, 1969, 3, No. 2.

Mutimer, D., Laughlin, L. and Powell, M.: Some Differences in the Family Relationships of Achieving and Underachieving Readers. Journal of Genetic Psychology, 1966, 109, 67-74. Nash, J.: The Father in Contemporary Culture and Current Psychological Literature. Child Development, 1965, 36, 261-297.

Nash, J. and Hayes, F.: The Parental Relationships of Male Homosexuals: Some Theoretical Issues and a Pilot Study. Australian Journal of Psychology, 1965, 17(1), 35-43.

Nelson, E. A. and Maccoby, E. E.: the Relationship Between Social Development and Differential Abilities on the Scholastic Aptitude Test. Merrill-Palmer Quarterly, 1966, 12, 269-289.

Nye, F. I.: Family Relationships and Delinquent Behaviour. New York: Wiley, 1958. O'Connor, P. J.: Aetiological Factors in Homosexuality as Seen in R.A.F. Psychiatric Practice British Journal of Psychiatry, 1964, 110, 381-391.

Pederson, F. and Robson K.: Father Participation in Infancy. American Journal of Orthopsychiatry, 1969, 39(3), 466-472.

Radin, N.: Father-child Interaction and the Intellectual Functioning of 4-year Old Boys. Developmental Psychology, 1972, 6(2), 353-361.

Radin, N.: Observed Paternal Behaviours as Antecedents of Intellectual Functioning in Young Boys. Developmental Psychology, 1973, 8(3), 369-376.

Reuter, M. and Biller H.: Perceived Paternal Nurturance-availability and Personality Adjustment Among College Males. Journal of Consulting and Clinical Psychology, 1973, 40(3), 339342.

Robins, E., Schmidt, E. H. and O'Neal, P.: Some Interrelations of Social Factors and Clinical Diagnosis in Attempted Suicide. American Journal of Psychiatry, 1957, 114, 221-231. Rosenberg, M.: Society and Adolescent Self-image. Princeton: Princeton University Press, 1965.

Santrock, J.: Paternal Absence, Sex-typing, and Identification. Developmental Psychology, 1970, 2(2), 264-272.

Santrock, J.: Relation of Type and onset of Father Absence to Cognitive Development, Child Development, 1972, 43, 455-469.

Schvansveldt, J., Fryer, M. and Ostler, R.: Concepts of 'Badness' and 'Goodness' of Parents as Perceived by Nursery School Children. Family Coordinator, 1970, 19, 98-103.

Shaw, M. C. and White, D. L.: The Relationship Between Child-parent Identification and Academic Underachievement. Journal of Clinical Psychology, 1965, 21, 10-13. 
Siegman, A.: Father Absence During Early Childhood and Antisocial Behaviour. Journal of Abnormal Psychology, 1966, 71, 71-74.

Solomon, D., Hirsch, J., Scheinfeld, D. and Jackson, J.: Family Characteristics and Elementary School Achievement in an Urban Ghetto. Journal of Consulting and Clinical Psychology, 1972, 39(3), 462-466.

Stephens, W. N.: Judgements by Social Workers on Boys and Mothers in Fatherless Families. Journal of Genetic Psychology, 1961, 99, 59-64.

Sutton-Smith, B. Rosenberg, B. and Landy, F.: Father Absence in Families of Different Sibling Compositions. Child Development, 1968, 39, 1213-1221.

Tasch, R.: The Role of the Father in the Family. Journal of Experimental Education, 1952, 20(4), 319-361.

Trunnell, L.: the Absent Father's Children's Emotional Disturbances. Archives of General Psychiatry, 1968, 19(2), 180-188.

West, D. J.: Parental Relationships in Male Homosexuality. International Journal of Social Psychiatry, 1959, 5, 85-97.

\section{Footnote}

Send requests for reprints to Dr. Anees A. Sheikh, Department of Psychology, Marquette University, Milwaukee, Wisconsin, 53233. 